Olli Lagerspetz

olli.lagerspetz@abo.fi

\title{
Wittgenstein's Forms of Life: A Tool of Perspicuous Representation
}

\section{Abstract}

The focus is on two texts by Wittgenstein where "forms of life" constitute the pivot of an extended argument: "Cause and Effect" and the discussion of colour concepts in "Remarks on the Philosophy of Psychology". Wittgenstein's take on causality is compared with G. H. von Wright's interventionist account. Wittgenstein's remark that forms of life must be accepted is a remark on philosophical method. Philosophy is a descriptive, non-reductive enterprise: philosophy aims to identify what escapes reduction in a given inquiry. At the same time, Wittgenstein's remark is directed against foundationalist conceptions of "the given" - especially, the Empiricist idea of simple experience as the rock bottom of knowledge. A form of life is given, not because it cannot be analysed further, but because it constitutes the form of the given investigation. Thus philosophical focus is shifted from justification to the activities of inquiry as such. Wittgenstein pursues this line of investigation further in On Certainty and in Remarks on Colour. The two currently dominant interpretations of "forms of life" are the "linguistic community" view and the "naturalist" view. Neither view has credible backing in textual evidence. Both imply a form of foundationalism, in contrast with Wittgenstein's idea of a descriptive method.

\section{Keywords}

Wittgenstein, forms of life, causality, colour, G. H. von Wright, Bertrand Russell, empiricism, foundationalism, philosophical method 


\section{Forms of Life and the Descriptive Ideal}

\subsection{Why "Forms of Life"?}

The main body of this paper is devoted to specific case studies. The purpose is to outline how Wittgenstein employs "forms of life" as a tool of philosophical clarification. I suggest that his guiding question is, "What are you looking for when you analyse the meaning of a concept - such as 'causation', 'colour', 'motive for action'?" To undertake a philosophical analysis of a concept is to investigate how questions and answers about it arise. What are the problems the concept solves? What new problems does it create in our activities (cf. RPP I: \601; PI, I: \570)? By placing concepts in the context of our practical methods of inquiry, Wittgenstein breaks the hold of the idea that we should look for a foundation for them in something immediately "given".

This is not the usual perspective of the interpretive literature. Interpreters have mostly seen forms of life as independently existing (cultural or biological) structures that explain language use. The focus has been on such questions as how to define forms of life; whether they are culturally specific or universal; whether they are rooted in human biology. According to Jocelyn Benoist (2018: 156), a kind of reductionism "seems to be widespread" in this context: "Life is supposed to be something basic - as it certainly is. Thus, to talk of 'forms of life', is to talk of something to which allegedly more complex activities or realities could be reduced".

In the literature, views on "forms of life" are not quite settled. Niklas Forsberg identifies the most visible fault line at present. On the one hand, there is an older interpretation of Wittgenstein, associating forms of life with linguistic or cultural communities:

If there is a standard account of Wittgenstein's idea of forms of life, it is that the meanings of our words are communal and that sharing a language means sharing a worldview. This is not exactly false, but it easily leads us into questions concerning linguistic and cultural relativism on the one hand and to a specific charge of conservatism (that is often directed against so-called ordinary language philosophies) on the other. (Forsberg 2012: 11) 
This might be termed a "linguistic community" view, stressing the plurality and possible incommensurability of forms of life. Thus, for Hans-Johann Glock, "'a form of life is a culture or a social formation, the totality of communal activities into which languagegames are embedded" (1996: 125, italics omitted). The charge of conservatism has been refuted many times over and should not detain us. The obvious point of reference here is Gellner's frontal attack on "ordinary language philosophers", including Wittgenstein, in Words and Things (1959) and later (on Gellner specifically, see Uschanov 2002).

Following Cavell (2013: 41), Forsberg outlines and endorses an alternative view where form of life is nature, not convention:

We agree and disagree; but these agreements and disagreements seem to have a common ground, or backdrop, against which they make sense. [...] Our form of life is social, and so is language. But our form of life is also nature, and so is language. [...] It is something that surrounds us and guides us without reflection, tacitly, naturally. It is natural. (Forsberg 2012: 11, 12, 13)

The emphasis here is more on the singular than the plural - our form of life, the human form of life. In some sense, "form of life" becomes an ethical umbrella concept, implying ideas of human and/or animal flourishing. It takes over some features of the traditional notion of human essence or human nature (cf. Foot 2001: 26-27, 91-92).

Most of those who participate in the interpretive debate today see this question of plurality versus unity as a central cause of disagreement (Biletzki and Matar 2018. See further Boncompagni 2015: 160, Moyal-Sharrock 2015: 26-30, Hacker 2015: 15-16). These two standpoints are interesting, and one should assess them on their own merits. It might also be worthwhile to trace the midand late Twentieth-Century philosophical debates that gave rise first to the one and then to the other: presumably, the relativism controversies and, somewhat later, the revival of Aristotelian ethics. However, the debate is, overall, rather alien to Wittgenstein's concerns.

Two documents are of particular interest for understanding Wittgenstein's employment of "forms of life": the manuscript 
notes published as Cause and Effect: Intuitive Awareness (CE) and the occurrence of forms of life in Remarks on the Philosophy of Psychology, Volume I (RPP I). In the former, forms of life are at the centre of an extended argument. The latter contains Wittgenstein's most explicit formulation of what he wanted to do with "forms of life".

\section{2 "What Has to Be Accepted"}

Famously, Wittgenstein writes, "What has to be accepted, the given, is - so one could say - forms of life" (PI, II: 226, cf. RPP I: \ 630). What does "accepting" mean here? Does it imply quietism, perhaps the kind of conservatism that Forsberg identifies as a problem? The demand merely to leave forms of life alone would be both unintelligible and dogmatic. Unintelligible, because we would not know what to accept (nor what "accepting" means) unless we had descriptions of the thing we should accept. Dogmatic, because we have no reason to accept forms of life until we understand their role in the investigation. In the context, however, it is obvious that Wittgenstein is not telling us not to question, analyse or describe forms of life. He is trying to formulate his view on philosophical method. To do descriptive philosophy is to identify what escapes reduction in a given inquiry.

The remark that certain things must be accepted seems, for one thing, to be Wittgenstein's response to issues of reductionism and "craving for generality", addressed in the Blue Book in 1933-34:

Philosophers constantly see the method of science before their eyes, and are irresistibly tempted to ask and answer in the way science does. [...] I want to say here that it can never be our job to reduce anything to anything, or to explain anything. Philosophy really is 'purely descriptive'. (BBB: 18)

Wittgenstein's critique targeted, among other things, the idea proposed by "popular scientists" that apparently solid objects are really not solid at all but "consist of particles filling space so thinly that it can almost be called empty" (BBB: 45). The scientist Wittgenstein had in mind was A. S. Eddington (1929: ix-x), who had stated that his writing desk was merely a swarm of particles. Wittgenstein's recipe for tackling this claim was to attend to the application of ideas of solidity. If the question is, "What is solidity?", 
answers should start by identifying things that we in fact call "solid" and investigating the implications of "solidity" in those cases. To do otherwise would be to analyse something else, not solidity.

But it is not immediately obvious how ordinary macro-level ideas translate to particle physics. For instance, we should not think of subatomic particles as tiny objects - the same as large objects, only much smaller. Eddington had accepted a simplified idea of what the everyday concept of solidity was, requiring a compact and entirely homogeneous body all the way down to the micro level. Leaving the everyday concept "as it is" is compatible with - and actually requires - identifying areas where its application might be a matter of debate.

That something must be "accepted" (das Hinqunehmende) - or, to offer alternative translations: included, taken into account - is a natural corollary to Wittgenstein's understanding of philosophy as a descriptive enterprise.

\section{Certainty as the "Prototype"}

\section{1 "Intuitive Knowledge" vs "Intuitive Awareness"}

Among the first occurrences of "forms of life" in Wittgenstein's writings is in the text published as Cause and Effect: Intuitive Awareness. In these raw manuscript notes, written in 1937, Wittgenstein takes issue with Russell's (1936) recent paper, The Limits of Empiricism.

David Hume, famously, had argued that the idea of a causal relation is not the result of experience. Nevertheless, causation, or something like it, seems very central to any kind of empirical knowledge beyond what is immediately available in the present. Russell had argued elsewhere (1912) that, in scientific theory, causality was no longer useful and was being replaced by notions of functional relationship. However, "something which we may call the 'uniformity of nature' is assumed" (Russell 1912: 15). As he now put it, "The possibility of empirical science [...] depends upon 
the possibility of perceiving causal or quasi-causal relations" (Russell 1936: 137). If all knowledge comes from experience, empiricism is left with a yawning gap in its very core.

It seems clear, therefore, that we all in fact are unshakeably convinced that we know things which pure empiricism would deny that we can know. We must accordingly seek a theory of knowledge other than pure empiricism. (Russell 1936: 148)

The concept of causality, as a relation where one event produces another, is the concept of some sort of dependence, not merely of constant conjunction. Wittgenstein's "Lectures on Aesthetics", which he held a few months after penning down Cause and Effect, contain a lengthy digression on causality. There he puts it thus:

'It's only concomitance' shows you think it can be something else. [...] Saying this shows you know of something different, i.e. connection. What are they denying when they say: "There is no necessary connection"? (LC: \22)

Russell's conclusion had been that, in order to arrive at the idea of uniformity in nature, we need at least some instances where we see a causal relation, or something like it, immediately. Perhaps "we can sometimes perceive relations which are analogous to causation", such as the experience of being hurt and crying out, where the one event (being hurt) "“produces' the other" (Russell 1936: 149). - This was the "intuitive knowledge" that Wittgenstein was addressing.

For Wittgenstein, Russell's invocation of intuitive knowledge was simply a stopgap measure to block the inevitable sceptical conclusion. Wittgenstein responded (CE: 393) with a quote from Goethe's Faust:

For where concepts are lacking,

We shall always find a word in good time.

Wittgenstein's suggestion is that we instead look at the "game" where words like "knowing" are used (CE: 393). His argument is rather sketchy here, but the main point is easily seen from $O n$ Certainty (e.g., OC: $\iint 243,403$ ) - as well as several places elsewhere in Wittgenstein's writings (PI, II: 221). "Knowledge" does not denote a particular state of one's mind, achieved intuitively or otherwise. "Knowledge" is something like substantiated opinion, 
implying that evidence might be invoked (CE: 391). The general idea of a causal nexus does not rely on evidence and hence is not knowledge; rather it is one of the things presupposed when we cite evidence. The crucial task for Wittgenstein will be to describe the forms of looking for evidence of what is the cause of what.

Having disposed of Russell's intuitive knowledge, Wittgenstein nevertheless agrees that Russell has a point. We need cases where causation is not doubted. To speak of intuitive knowledge is out of place here, but "intuitive awareness" (intuitives Erfassen) (CE: 377) describes the basic form of the game of cause and effect. It is one where we act naturally or intuitively. Moreover, you cannot introduce doubt into that basic form without sabotaging it. As an analogy, Wittgenstein thinks of traffic on roads. Traffic is organised on the assumption that vehicles are on their way somewhere. Motorists do not constantly reconsider their plans and turn around (CE: 379). Exceptions to rule are possible once the rule is definitely in place. These arguments point towards the more at-length treatment of certainty and doubting in the later work published as On Certainty.

\section{2 "Urform" and "Urpflanze"}

"Forms of life" enter in this passage:

I want to say: it is characteristic of our language that the foundation on which it grows consists in steady forms of life ${ }^{1}$, regular ways of acting.

Its function is determined above all by the action which it accompanies.

We have an idea of which forms of life are primitive, and which could only have developed out of these. We believe that the simplest form of plough existed before the complicated one.

(CE: 397, translation modified)

The method to investigate the function (and hence meaning) of our talk of causality is to relate it to meaningful patterns of action. The "cause-effect game" has a simple "prototype", Urform (CE: 397).

${ }^{1}$ Lebensformen, in CE translated as "ways of living". 
Urform carries an association to Goethe's notion of a primal plant or Urpflanze. Wittgenstein often cited Goethe's idea in his reflections on philosophical method. In his Metamorphosis of Plants, Goethe (1926-1934, XVI: 199-383) had argued that all existing plants were modifications of one simple form. The primal plant was a theoretical construct, but Goethe also believed it "must" exist - "for otherwise how should I recognise that this or that formation is a plant, unless they were all formed according to one pattern?" ("Italienische Reise", in Goethe 1926-1934, IV: 7-585, at p. 281, 17 April 1787; cf. p. 341, 17 May 1787). On his travel to Italy, Goethe hoped actually to find a primal plant somewhere in the fertile soil of that country. Under the influence of Schiller, Goethe later revised his understanding of what the primal plant was (Goethe, "Glückliches Ereignis", in Goethe 1926-1934, XVI: 20-24). What he had really sought had been a "concept" or "idea". As Wittgenstein would put it, the primal plant was a connecting link creating a "perspicuous representation" (übersichtliche Darstellung) of the vegetable kingdom (cf. CE: 132-133, RPP I: \ 950). The connection was not dependent on the hypothesis that a primal plant was once physically in existence.

Danièle Moyal-Sharrock (2015: 34) suggests a straightforward evolutionary reading of Wittgenstein on this topic. Linguistic forms develop from language-less forms of action: "[A]s we evolved from proto-linguistic into linguistic forms of communication, different languages embedded in specific cultural norms and values emerged". Just as, for Wittgenstein, "the simplest form of plough existed before the complicated one", she argues that "our 'complicated' form of life can only have developed from a more primitive, language-less, form of life" (Moyal-Sharrock 2015: 30).

Two objections are relevant here. First, while it certainly makes sense that humans once had non-human ancestors who did not use language, this does not seem to be what Wittgenstein is getting at. The contrast in the quoted passage is not one between having a language and not having one, but between complex and simple forms of life, all of which may involve language (see Benoist 2018: $164,167)$. 
Secondly, Moyal-Sharrock's embrace of the evolutionary scenario as the "only" one possible is different from Wittgenstein's cautious approach. When the latter argues, "we believe" that simple forms came before complex ones, he is not stating his views about the actual course of events. (As a generalised hypothesis about the development of material culture, it would be empirically false - it is easy to come up with examples of a reverse development.) Wittgenstein indicates a contrast between simple and complex, one with a special place in thinking. In the same vein, he comments on the attractions of evolutionary theory in his "Lectures on Aesthetics". The public mostly did not receive Darwinism as a testable hypothesis. For its adherents, it had all the appeal of a selfevident truth due to its reference to a "single principle" and "the enormous charm of this unity" (LC: 26, fn6).

Comparisons with Wittgenstein's take on the Urpflanze should caution us against interpreting the relation between simple and complex forms of life in terms of a temporal sequence.

\section{The Game of Cause and Effect}

\section{1 "Word" and "Deed"}

The "basic form" (Grundform) or "primitive form" (primitive Form) of the language game of cause and effect is "one in which we act" (CE: 397). In an oft-quoted passage, Wittgenstein focuses on the role of "reaction", ending once again with a Goethe quote:

The origin and the primitive form of the language game is a reaction; only from this can more complicated forms develop.

Language - I want to say - is a refinement. "In the beginning was the deed".

(CE: 395; CV: 36) ${ }^{2}$

\footnotetext{
${ }^{2}$ Wittgenstein uses this Goethe quote also in OC. In that context, Wittgenstein takes up the idea that "all operating with thoughts (with language)" implies "propositions of the form of empirical propositions" ( $($ 401) but continues $(\$ 402)$ by apparently suggesting that their certainty is constituted by the "deed" of acting with certainty.
} 
"The deed", of course, stands in contrast with the opening words of the Gospel of John, "In the beginning was the Word" as standardly translated. One might think Wittgenstein is dismissing language as a surface phenomenon, in favour of instinctive behaviour. Thus, Malcolm (1995: 69) states that causal expressions are "grafted on to these immediate reactions". Such contrasts, however, are problematic by Wittgenstein's own lights, not only

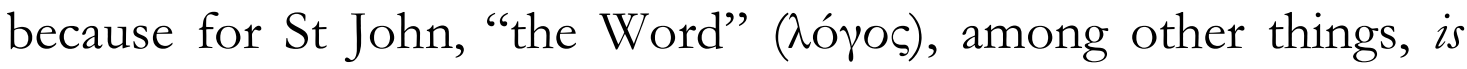
Divine action. In fact, Dr Faust, in the scene Wittgenstein is considering (Goethe 1926-1934, VI: 169), offers "Deed" as his own, inspired translation of the Greek word (along with "Sense" and "Power").

For Wittgenstein, too, language is action, and the notion of a language game is introduced precisely in order to highlight that "the speaking of a language is part of an activity, or of a form of life" (PI: \23). Thus, "[t]he essence of the language game is a practical method (a way of acting) - not speculation, not chatter" (CE: 399). This is not a contrast between language and a silent way of acting but one between idle talk (Geschwäts) and "method" -

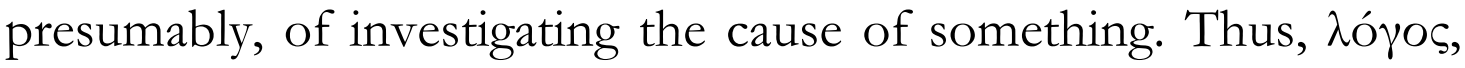
not in the restricted sense of "word" but as a complex of language, thought and meaningful action, still stands in "the beginning".

Wittgenstein discusses a variety of cases. There is a certain ambiguity here, which he notes:

There is a reaction which can be called 'reacting to the cause'. - We also speak of 'tracing' the cause; a simple case would be, say, following a string to see who is pulling at it. (CE: 387)

Wittgenstein's examples of "reacting" include recognising that pain results from a blow we received, and instinctively looking from what was hit to what has hit it. We "instinctively get rid of the cause if we don't want the effect" (CE: 373). We "involuntarily look towards a particular spot" which appears to be the source of a sound (CE: 377). In "Lectures on Aesthetics", Wittgenstein discusses examples of aesthetic behaviour, which he similarly describes as reactions (LC: p. 13, \11; p. 14, \$15). He generally emphasises that aesthetic reactions are cultivated in specific cultural 
milieus. A "natural" (immediate) reaction may be culturally mediated just as much as a more complex procedure might be.

One might of course say that no language game would ever get started if speakers never reacted to anything. To react is, in a sense, to acknowledge a cause - that is, to acknowledge whatever triggered the reaction. Conversely, if no trigger is there, we will not speak of a reaction but of spontaneous movement. Nevertheless, the second sentence in the quoted paragraph demonstrates that "reaction" is still not the right word for describing a crucial aspect of the prototype: also "tracing" is involved. On Wittgenstein's view, the concept of causation implies inquiry: "[t]he game of 'looking for the cause"' (CE: 395).

\subsection{Wittgenstein's Typology of Cases}

The forms of life of "causation" are irreducible, but not unanalysable. In the text published together with Cause and Effect as "Appendix A" (CE: 406-411), Wittgenstein offers a typology of cases (CE: 410, emphases in the original):

(a) Reacting, "looking from one thing to another thing".

(b) Tracing, "following a particular kind of mechanism". 3

(c) Experimenting in order to "predict".

"Lectures on Aesthetics" (LC: p. 13, \ 12 and fn4) present a largely similar list of uses of the word "cause".

We already saw the contrast between reacting, as in (a), and looking for a cause, as in (b)-(c). There is also an important difference between (b), "tracing" and (c), "predicting". To verify a causal connection by "tracing" is not a matter of looking for correlations. We perceive the connection as inherent in a system. For instance, movement continues from one part to the next in a piece of machinery. The movements of parts are identifiable a

\footnotetext{
${ }^{3}$ A further category in CE is "[i]mpact" (p. 410), which Wittgenstein identifies as the favoured model of explanation in mechanics. It seems, however, that "impact" can be included as a sub-category under the head of "tracing".
} 
priori if the structure is known (CE: 399), perhaps from a drawing. We "use the machine as a symbol of a way of moving" (CE: 401). In a real situation, machine parts may wear out and get bent (CE: 395), but in the drawing the machine is "ideally rigid" (PI, I: \194) by "logical necessity" (LC: p. 16, \27).

Cases that fall under (c), "predicting", come closest to the Humean idea of constant conjunction. They involve checking for correlations between temporally successive events. This may be a complex and intellectually demanding procedure, but there is still a kind of intuitive certainty. We cannot help thinking that there must be a cause. Under this heading, we find a reference to the case where "the seeds of an A-plant produce A-plants, the seeds of a Bplant, B-plants" (as formulated on p. 375). If two different kinds of plant spring up from the two samples, we assume the seeds must have been different from the start.

Suppose no difference is found? Wittgenstein argues that "today", we would "look frantically for a difference". We insist that there must be one because,

There is an ideal - a direction in which investigations are constantly pushed. "There must be" corresponds to this ideal. (CE: 411)

Universal causation is not a discovery that scientists have made. It is more like a requirement: We go on looking until we find something that would be acceptable as a cause. The "law" of causality is not the result of looking, but the form of looking (cf. OC: \$167). Still, it is possible to imagine "circumstances where we would break with this tradition" (CE: 411). This is not surprising, for even today, there are such circumstances. We sometimes put down unexpected occurrences to "chance" - although this, too, is something we must learn to do. A complete break with the "tradition" does not seem to be in the cards, however, as that would imply giving up on looking for causes altogether.

\footnotetext{
${ }^{4}$ Translation modified. - This seems to involve "predicting" in two ways: (1) When we see the fully-grown plants, we "predict" (assume) that one of them sprang from a seed taken from an A-plant and another from a seed from a B-plant. (2) We predict that seeds continue to produce offspring of the same type as the plant from which we took them.
} 


\section{Essence Unfolding in Action}

\subsection{Comparison with von Wright}

Wittgenstein's take on causality is reminiscent of Georg Henrik von Wright's "actionist" or "experimentalist" account in his book Causality and Determinism (von Wright 1974: 57). von Wright does not cite Wittgenstein in this connection, but one cannot rule out a Wittgensteinian influence, either from discussions or through von Wright's subsequent work as editor of his manuscripts. Like Wittgenstein, he locates the origin of the idea of causation, not in theoretical reason but in a practical method. We hope for a certain result, $q$, and "that $p$ is the cause of $q,[\ldots]$ means that I could bring about $q$, if I could do (so that) $p$ " (von Wright 1971: 74). Thus, "it is only through the idea of doing things that we come to grasp the ideas of cause and effect" (von Wright 1971: 81-82). An implication of this view is that universal determinism, leaving no conceivable room for free action, is literally un-thinkable, because for von Wright (1974: 136), "the concept of cause presupposes the concept of action".

von Wright's view has been accused of anthropomorphism perhaps predictably in the context of the late-Twentieth Century dominance of naturalism. The same objections, if convincing, would apply mutatis mutandis to Wittgenstein. Don't these views imply that no causation would take place in a world bereft of human agency? What about causality in natural processes? Would causal relations be different if people just had different ideas of what is the cause of what? Moreover, human action results in changes precisely because of causal relations - hence causality must be operative in the world before human beings can get it into their heads to take action.

Marco Buzzoni (2014) has recently published a cogent defense of von Wright's position. For the present purpose, it is enough to note that von Wright consistently distinguishes between "epistemic" and "ontic" issues. The argument is about "the concept of" cause, not about whether the world as such is causally organised (von Wright 1974: 136). It will of course have to be, well, "anthropomorphic" - if it is about how buman beings engage with 
the concept of causality. What he says is, roughly, that in order to understand the concept of causal dependence - how that concept is different from that of co-variance or functional relationship - we must consider its role in action. This does not mean that the concept of causation is not applicable where human intervention is absent; but our understanding even of those situations follows the model of intervention.

Now one might suggest that the actionist view on causation presupposes that at least some very general principles hold concerning the ontological structure of reality. von Wright in part goes along with this idea. The world must be such that intervention is possible. It must exhibit a sufficient degree of regularity for the concept of causation to be useful (von Wright 1974: 54-57).

However, it seems misleading to say there must be enough regularity in nature to justify the concept of causation. The amount of regularity we find in nature is itself a function of the kinds of thing we are prepared to accept as cases of causal influence (see Dilman 2002: 64-66). In the end, to say, "the world must be such that the concept of causation is applicable" is, perhaps, just to say that we wouldn't have a concept of causation unless we had one.

If the question is, "What is causation?", we can sum up what is philosophical about it in the question, "What do we mean by causation?" In other words, what is the use or function of the concept of causation? We answer this question precisely by looking at activities where the concept has a role. Causation just is the kind of "thing" we look for in these-and-these ways. If the next question is, "Then, is that 'thing' there - really, 'in the world'?" - the answer is: "This is the concept of causation; judge for yourself if you have use for it."

\subsection{Measuring}

Wittgenstein's discussion of forms of life in RPP $I$ includes considerations about the interdependence of the concepts of "length" and "measuring". His argument here looks closely analogous with the one just presented. To be sure, our methods of determining the length of something presuppose that we recognise "length" regardless of any specific method. "[O]ne can't explain what 
length is by means of a method of determining length" (RPP I: $\int$ 632) - presumably because the explanation would be understood only by someone who already has some idea of what "length" means. Yet on the other hand, "What 'determining the length" means" is not learnt by learning, first, what length is and, then, separately, what determining is -

rather one learns the meaning of the word "length", among other things, by learning what determining the length is: "Refining the determination of length' is a new technique, which modifies our concept of length. (RPP I: $\$ 632, cf. PI, II: 225)

For this reason, '[n]ot only a physical investigation, but also a conceptual one, can be called "methodological investigation" (PI, II: p. 225). The relationship between the concept and the method is one where they mutually define each other. If you want to know the length of a dining table you can use a measuring tape, but you give the length of a telephone number (being an abstract object, not physical) in digits, not inches. The two methods imply two concepts of length, or two applications of the concept. In this sense, "Essence is expressed by grammar" ... "Grammar tells us

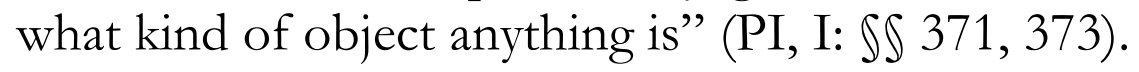

You might say that in order to take measurements you need objects that fit the measuring practices. You need a certain degree of constancy in the environment. However, this cuts both ways. The stability of objects does not justify the concept of length, but rather our methods of applying the concept of length define what, in a given case, counts as stability. "Stability" of the relevant kind is understood with reference to the measuring methods in use.

\section{Simple Experience versus the Game with Colours}

\subsection{Colour as "Given"}

The statement that forms of life need to be accepted occurs for the first time (May 1946 to October 1947) in RPP I. The paragraph contrasts two ideas of where to localise the thing to be "accepted": 
Instead of the unanalysable, specific, indefinable: the fact that we act in such-and-such ways, e.g. punish certain actions, establish the state of affairs thus and so, give orders, render accounts, describe colours, take an interest in others' feelings. What has to be accepted, the given - it might be said - are facts of living // forms of life. (RPP I: \630)

This is a remark about philosophical method and the place in it for "the given" - "the last point beyond which I can push no further" (WWK: 97). For the Empiricists, "simple ideas" were a necessary stopping place for any investigation of human knowledge. Wittgenstein considers the idea - once more originating in Humean philosophy and carried forward by Russell - that colour impressions are such unanalysable simples (RPP I: SS 602-630, 634). Russell, in his essay, "Knowledge by Acquaintance and Knowledge by Description", had maintained that to see a colour is already to have full knowledge of it, without anything else being required or even possible (Russell 1923: 73-74; cf. Z: \332, RPP I: \644). As Wittgenstein described such views: "Knowing is here like having; having in yourself" (CE: 418). This view on knowledge and its foundation in "the given" of course was a main target of Wilfrid Sellars' subsequent attack in "Empiricism and the Philosophy of Mind" (1963: 129-130 and passim).

The colour I am now seeing may strike me as "the specific, the unanalysable". We should, however, not stay there but "[a]sk instead how it comes about that we want to say this. And the answer to that is not difficult to find" (RPP I: \ 634). Wittgenstein is apparently thinking of the hold that the idea of private ostensive definition has on us (PI, I: $\int 380$ ). In philosophy, there is an introspective tradition - to which Russell belonged - of arresting oneself before a specific moment of experiencing, declaring that it must escape any further analysis. However, we should not think we grasp the essence of red by concentrating very hard on our experience of red. If you say of a red object, "that is something specific", your statement is intelligible only to someone who already has an idea of why you would say it, "the use of that sample" (Z: \333).

To identify a sample as "red" is to name an element. Naming, in this case, "is a preparation for description". 
Naming is so far not a move in the language-game - any more than putting a piece in its place on the board is a move in chess. We may say: nothing has so far been done, when a thing has been named. (PI, I: \49)

Of course, if the entire game just consists in (a pretence of) naming uttering a word with one's eyes fixed on a coloured surface - it will indeed lie in the nature of that game that nothing can be added. However, the "unanalysable" character of red is here simply a consequence of the arbitrary decision to restrict the game in that way.

Wittgenstein takes up the question of the "immediately given" already in 1930 with Waismann and Schlick (WWK: 97-98, 22.3.1930). The verification of "This is yellow" (or red) has the same multiplicity as the different roles that the sentence itself can take. The fact that I see yellow at a specific spot is a verification, the endpoint of an investigation, only if it is already established that it cannot, for instance on chemical grounds, be argued that the spot I see as yellow is really another colour.

We must consider what purpose the description serves. Whether it is complete or incomplete - whether or not you have reached rock bottom - is always relative to that (RPP I: \ 636).

\subsection{The Status of Colour Descriptions}

The entries on colour included in RPP I offer nothing similar to the typology of cases listed in Cause and Effect. The same is true of Zettel, $\iint 331-370$, which in part overlaps with the discussion in RPP I. It seems that Wittgenstein was still looking for a settled view on colour descriptions. A kind of synthetic a priori was haunting him. Are colour concepts (and the relationships between them) conventional - based on agreement between speakers - or are they inherent in the nature of things? (Z: $\left.\iint 357,331\right)$.

Wittgenstein delves into questions about colour more deeply not many years afterwards, in his Remarks on Colour (ROC). ${ }^{5}$ A kind of programme for that work is already included in RPP I. Wittgenstein suggests that we can circumvent the conundrum

\footnotetext{
${ }^{5}$ See Lee (1999) for an inspiring overview of ROC.
} 
about the status of colour descriptions if we focus, not on colour as a simple experience but on the form of life, "the game with colours":

"Colours are something specific. Not to be explained by something else." How is this instrument used? - Describe the game with colours. The naming of colours, the comparison of colours, the production of colours, the connexion between colour and light and illumination, the connexion of colour with the eye, of notes with the ear, and innumerable other things. Won't what is 'specific' about colours come out in this? How does one shew someone a colour; and how a note? (RPP I: \628)

The idea of specific, "pure" colour concepts - describing colour and nothing but colour - has a connection with the fact that we can identify a "this", the object that might have some other colour instead (WWK: 97). We can change surface colours of objects in arbitrary ways without, at the same time, modifying their shapes. It also appears that the meaning of the "primary vs mixed colour" distinction is linked to the practical fact that we can reproduce colours by mixing from two or three primaries. This reasoning is reminiscent of Wittgenstein's take on causality: We want a certain effect - to mix or find (ROC, I: \8) a pigment to match an existing sample. "Red" might be primary in one such game but not in another. On the other hand: Games in which "red" is primary seem to be quite important whereas it is more difficult to find games where red counts as mixed. ${ }^{6}$

If a certain shape and a certain colour always went together, we might not have a specific colour word for that colour, but only a word for colour and shape combined (RPP I: \47, cf. Z: \\ 331, 334, 337). In RPP and Zettel, these are only imaginary possibilities. Remarks on Colour takes up actual instances of colour words that include dimensions other than "pure" colour - including transparent vs opaque colours and "amber colour", which is impossible without the depth dimension (ROC, III: IS 150-151).

\footnotetext{
${ }^{6}$ According to Wittgenstein, thinking of 'red' as composite is "a language game that we cannot learn" ( $($ 606). - This is not quite correct, however. In colour printing (the CMYK system), all colours are produced by mixing cyan, magenta, yellow and black on a white background. Red is a composite from the primary colours yellow and magenta.
} 
"What I really want to show here is that it is not at all clear a priori which are the simple colour concepts"; "There is no such thing as the pure colour concept" (ROC, III: $\iint 69,73$ ).

By considering the great variety of our practical engagements with colour, Wittgenstein breaks the hold of the idea that colours are reducible to an unanalysable rock bottom experience. Colour descriptions have very different functions, something which surfaces in the "indeterminateness of our concept of sameness of colour" (ROC, I: \56, also see I: \ 17, III: \ 78). While the phrase, "form of life", does not occur in Remarks on Colour, that work clearly offers an analysis of the "forms of life" in which "we [...] describe colours" (RPP I: \630).

\section{Wittgenstein's Shift of the "Given"}

\subsection{The "Given" as the Form of Inquiry}

Wittgenstein's disagreement with Russell is not merely about what kinds of thing constitute "the given" but about the function of the idea of givenness. Russell was working within a general philosophical tradition of foundationalism. In that tradition, our assumptions of, for instance, causes are justified if an ultimate foundation is identifiable: say, the ontological structure of reality, or - as with Russell - intuitive knowledge by acquaintance. Wittgenstein breaks with that tradition, but not by offering forms of life as the new foundation. To be sure, when we look for a cause or when we describe a colour, something is given. The "given" is, however, not something at the end of an investigation, but the form of the investigation. Later, the shift of focus from justification to the activity of questioning as such becomes the central theme of $O n$ Certainty.

If you ask, "What is causation?" the ontological structure of the world is irrelevant. What you need is an account of how we identify causes; also of the fact that it is sometimes misplaced to look for a cause. While avoiding issues of ontology, this line of philosophical inquiry opens up for new questions. It turns out that causality is not one thing, but just as many as are our ways of looking for 
causes. Colour is not one thing, but just as many as our ways of determining colours. We consider certain lines of inquiry as relevant, we have ideas of what counts as a satisfactory answer and its verification. What we need is an overview of this multiplicity.

Lars Hertzberg has argued that, in Cause and Effect, a crucial element is still missing: the role of public language in the creation of meaning. According to Hertzberg (2011: 367), "Wittgenstein, it seems, is trying to make a shortcut from the reactions of the individual to the language game of cause and effect". This critique might be to the point if Wittgenstein indeed had wanted to continue the foundationalist project by explaining the language game in terms of something more primitive. However, as I see it, that was not the purpose of his descriptions of "reactions to a cause".

The entire discussion in Cause and Effect is set in the context of scientific and everyday inquiries, including socially embedded traditions of testing and appealing to evidence. To be sure, Wittgenstein's examples appear only accidentally to concern human interaction (e.g., someone hitting you; following a thread and meeting someone at the other end). He does not say here that forms of life are something shared with other language users, even though he does say so elsewhere (PI, I: \241). As Hertzberg (1988) points out elsewhere, Wittgenstein highlights later, in On Certainty, explicitly the fact that the acquisition of knowledge takes place in a social context.

\subsection{Community versus Nature; and Foundationalism}

Looking at the interpretive debate, it is appropriate to ask whether it has fully managed to incorporate Wittgenstein's "shift of the given". The main thrust of the debate is that a form of life is an entity on which linguistic meaning rests. The debate has focused on identifying some such basic cultural or natural reality. The conflict between "linguistic community" and "naturalist" views is largely about how deep one should dig in one's search for the foundations of linguistic meaning. However, there is scant textual evidence for either view. 
The "linguistic community" view involves the assimilation of forms of life into ethno-cultural units, which may be as specific as "the Italians", "the Elizabethans", etc. (Moyal-Sharrock 2015: 33; Hacker 2015: 11). The starting point is the Wittgensteinian insight that "to imagine a language is to imagine a form of life" (PI: $₫ 19)$. However, I believe its application here depends on equivocation about "a language". When Wittgenstein stresses the internal relation between form of life and language, he always (in this sentence and elsewhere) thinks of the "language" at issue in terms of a specific function. ${ }^{7}$ He considers the language of the Builders, the language of giving orders and reports in a battle, etc. - not national languages like English or Italian (cf. Hacker 2015: 5). The alleged textual evidence for the interpretation of forms of life as ethnocultural units seems to be simply the fact that, in the Brown Book (BBB: 134), where forms of life are not mentioned, Wittgenstein equates "imagin[ing] a use of language" with imagining "a culture" (Glock 1996; Hacker 2015: 11) - which is surely reasonable but of no support here. ${ }^{8}$

The "naturalist" view, on the other hand, champions the idea of a universally shared life form, "the human form of life" (a phrase that Wittgenstein never uses). Again, there is not much in the sources to suggest that Wittgenstein's reason for introducing "forms of life" was to highlight something as the distinctive mark of the human. The main, rather ambiguous support comes in the second part of Philosophical Investigations, where "the phenomena of hope" (simpler in the life of a dog than of a human being) are described as "modes of this complicated form of life", which involves "the use of language" (PI, II: 174).

\footnotetext{
${ }^{7}$ One might suggest that "the community of mathematicians" is Wittgenstein's example of the communal base of a form of life (cf. PI, II: pp. 225-226). However, the community is, in this case, the group of those who participate in a certain kind of inquiry; the methods of inquiry constitute the group and not vice versa.

${ }^{8}$ See also LC, p. 8, \26: "What belongs to a language game is a whole culture". Another candidate for evidence might be included in LC, p. 58: "Why shouldn't one form of life culminate in an utterance of belief in a Last Judgement?" Taking this passage to support the "community" interpretation would presuppose (1) that Wittgenstein is speaking of the religious culture of a community and not of an individual's life stance specified by religious notions of ethical responsibility, conscience, etc.; and (2) that this interpretation should be generalised to other occurrences of "forms of life".
} 
Some commentators suggest that we nevertheless need to assume a universal human form of life in order to avoid cultural relativism (Moyal-Sharrock 2015: 39, Forsberg 2012: 11). This seems to me misguided. Each human activity or inquiry certainly is, in a sense, sui generis; but we move quite freely between activities in our daily lives, mostly with no sense of discomfort (e.g., first looking for causes and then for motives). The idea that intelligibility between life forms requires a shared, overarching life form seems to be a case of believing that there is no connection between two things unless both are somehow subdivisions of one and the same thing.

In the texts I have considered, Wittgenstein uses "forms of life" both in discussions of cases that may be culturally specific (e.g., different ways to divide the visible spectrum) and others that seem inescapable in any life we can think of (the idea of regularity in nature). There is no contradiction in this. In both cases, Wittgenstein invites us to look at action and the sense that the relevant concepts make there. On the other hand: If what you want is a systematic account of "the" relation between language and the world, or between linguistic communities - and if you expect forms of life to be constitutive elements in that - then Wittgenstein is bound to appear frustratingly vague.

Here one might ask, "If 'forms of life' were such an important tool for Wittgenstein, why wasn't he making more use of it?" The answer is, "He was making more use of it". There is clear continuity between the two manuscripts I have mainly considered, and his subsequent investigations in On Certainty and Remarks on Colour and his other later work as well. Analysing concepts by looking at their functions in our actions and inquiries is a consistent feature of Wittgenstein's way of doing philosophy from the 1930s onwards which does not imply he must tell the reader at every turn that this is what he is doing.

\footnotetext{
${ }^{9}$ Thanks to Graham Oddie, Jonas Ahlskog, Lars Hertzberg and to participants of the Philosophy Research Seminar at Åbo Akademi University. I wrote this paper mainly during my sojourn at Swedish Collegium for Advanced Studies (SCAS) at Uppsala in the Spring term of 2019, with support from Erik Allardt Fellowship.
} 


\section{References}

\section{WORKS BY LUDWIG WITTGENSTEIN}

BBB (1960). The Blue and Brown Books, Second Edition., New York: Harper \& Row.

CE (1993). "Cause and Effect: Intuitive Awareness". In: Ludwig Wittgenstein:

Philosophical Occasions 1912-1952, ed. J. C. Klagge \& A. Nordmann.

Indianapolis and Cambridge: Hackett, 1993, 370-405.

CV (1998). Culture and Value, Second edition. Oxford: Blackwell.

LC (1966). Lectures and Conversations on Aesthetics, Psychology and Religious Belief,

ed. C. Barrett. Berkeley and Los Angeles: University of California Press.

OC (1969). On Certainty. Oxford: Basil Blackwell.

PI (1953). Philosophical Investigations. Oxford: Basil Blackwell.

ROC (1991). Remarks on Colour. Oxford: Blackwell.

RPP I (1980). Remarks on the Philosophy of Psychology, Volume I. Oxford: Basil Blackwell.

WWK (1987). Ludwig Wittgenstein und der Wiener Kreis. Gespräche, aufgezeichnet von Friedrich Waismann. Aus dem Nachlaß herausgegeben von B. F. McGuinness. Frankfurt a. M: Suhrkamp. Z (1967). Zettel. Berkeley \& Los Angeles: University of California Press.

\section{OTHER WORKS}

Benoist, J., 2018. “Our Life with Truth”. In: C. Martin, ed., Language, Form(s) of Life, and Logic. Berlin: De Gruyter, 155-171.

Biletzki, A. and Matar, A., 2018. "Ludwig Wittgenstein". The Stanford Encyclopedia of Philosophy (Summer 2018 Edition), E. N. Zalta, ed. $<$ https://plato.stanford.edu/archives/sum2018/entries/wittgenstein/>.

Boncompagni, A., 2015. "Elucidating Forms of Life. The Evolution of a Philosophical Tool”. Nordic Wittgenstein Review 4, 155-175.

Buzzoni, M., 2014. "The Agency Theory of Causality, Anthropomorphism, and Simultaneity". International Studies in the Philosopby of Science, 28 (2014):4, 375-395.

Cavell, S., 2013. This New yet Unapproachable America: Lectures After Emerson After Wittgenstein. Chicago: University of Chicago Press.

Dilman, I., 2002. Wittgenstein's Copernican Revolution: The Question of Linguistic Idealism. Basingstoke: Palgrave.

Eddington, A. S., 1929. The Nature of the Physical World. New York: Macmillan. Foot, P., 2001. Natural Goodness. Oxford: Oxford University Press. 
Forsberg, N., 2012. "Different Forms of Forms of Life". In: N. Forsberg, M. Burley and N. Hämäläinen, eds., Language, Ethics and Animal Life: Wittgenstein and Beyond. London: Bloomsbury, 1-15.

Gellner, E., 1959. Words and Things. London: Victor Gollancz.

Glock, H.-J., 1996. "Form of Life". In: H.-J. Glock, A Wittgenstein Dictionary. Oxford: Blackwell, 124-129.

Goethe, J. W. von, 1926-1934. Goethes sämtliche Werke, Band I-XVII. Leipzig: Insel-Verlag.

Hacker, P., 2015. "Forms of Life". Nordic Wittgenstein Review 4, 1-20.

Hertzberg, L., 1988. "On the Attitude of Trust", Inquiry 31, 307-322.

Hertzberg, L., 2011. "Very General Facts of Nature”. In: O. Kuusela and M. McGinn, eds., The Oxford Handbook of Wittgenstein. Oxford: Oxford University Press, 351-372.

Lee, A., 1999. “Wittgenstein's Remarks on Colour”. Philosophical Investigations 22, 215-239.

Malcolm, N., 1995. "The Relation of Language to Instinctive Behaviour". In: N. Malcolm, Wittgensteinian Themes: Essays 1978-1989. Ithaca, NY: Cornell University Press, 66-86.

Moyal-Sharrock, D., 2015. "Wittgenstein on Forms of Life, Patterns of Life, and Ways of Living". Nordic Wittgenstein Review 4, 21-42.

Russell, B., 1912. "On the Notion of Cause". Proceedings of the Aristotelian Society 13, 1-26.

Russell, B., 1923. "Knowledge by Acquaintance and Knowledge by Description”. In: B. Russell, Problems of Philosophy. London: Williams and Norgate, 72-92.

Russell, B., 1936. "The Limits of Empiricism". Proceedings of the Aristotelian Society 36, 131-150.

Sellars, W., 1963. "Empiricism and the Philosophy of Mind". In: W. Sellars, Science, Perception and Reality. London: Routledge \& Kegan Paul, 127196.

Uschanov, T. P., 2002. "Ernest Gellner's Criticisms of Wittgenstein and Ordinary Language Philosophy”. In: G. N. Kitching \& N. Pleasants, eds., Marx and Wittgenstein: Knowledge, Morality and Politics. London: Routledge, 23-46.

von Wright, G. H., 1971. Explanation and Understanding. Ithaca, NY: Cornell University Press.

von Wright, G. H., 1974. Causality and Determinism. New York and London: Columbia University Press. 


\section{Biographical Note}

Olli Lagerspetz is Senior Lecturer and Docent of Philosophy at Åbo Akademi University, and Docent of History of Ideas at the University of Oulu. His most recent books are A Pbilosophy of Dirt (Reaktionbooks, 2018), Trust, Ethics and Human Reason (Bloomsbury, 2015) and, with Kirsti Suolinna, Edward Westermarck: Intellectual Networks, Philosophy and Social Anthropology (The Finnish Society of Sciences and Letters, 2014). 